\title{
CIDADES, Comunidades e Territórios
}

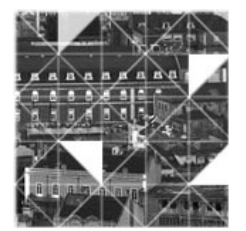

\author{
Valoración del Paisaje como Potencial Recurso de Desarrollo Sustentable. \\ Estudio de Caso en el sur de Chile. \\ Carolina Ojeda Leal ${ }^{1}$, Universidad de Valparaíso, Chile.
}

\begin{abstract}
The importance of environmental management has positive effects in many areas such as economic, governance, tourism, welfare, etc. In first place, the research develops the statement of the problem. The second stage involves the conceptual framework, which consists of a number of remarkable authors suggesting state-of-the art data of the problem being treated. The third stage describes the current state of the environment, the cultural and economic development of the study area, which in this case is Maullín, located in the Region of Los Lagos, Chile. Finally, a number of strategies of landscape as an economic resource that creates social development and sustainable material is proposed.
\end{abstract}

Keywords: Landscape; Sustainable Development; Chile; Landscape

Valorization, Landscape Planning.

\section{Introducción}

La subvaloración del paisaje por parte de sus habitantes crea una situación degradación ambiental del territorio (Leff, 2005: 11), y además, se convierte en un recurso de desarrollo económico desaprovechado (Mata, 2013). Las condiciones antes nombradas traen aparejadas un desinterés generalizado en la participación ambiental o en la pérdida de identidad cultural de esas comunidades (Guimarães, 1991: 20-23) las cuales responden a un cierto imaginario social asociado a formas de vida y producción tradicionales (Solano, 2011: 12; Lindón e Hiernaux, 2012: 8).

Para generar un tránsito desde esta situación negativa detectada en el círculo vicioso hacia un círculo virtuoso es necesario un cambio de paradigma (Nurkse, 1955: 45) que se inicia con una valoración de parte de los habitantes u ocupantes de sus paisajes la cual pasaría por el desarrollo de la propuesta de este proyecto. En el ámbito de la gestión del paisaje, el proceso de empoderamiento resulta indispensable para la puesta en marcha de una gestión sostenible de los paisajes (LPC, 2011: 9).

El objetivo general de la investigación es: Identificar estrategias de valoración del paisaje en la comunidad de Maullín como un potencial recurso económico. Proponer a partir del caso de estudio una serie de estrategias de valoración del paisaje como una alternativa de desarrollo económico. Los Objetivos Específicos son: Identificar algunas formas en que se valora y comprende el paisaje en la comunidad de Maullín, Chile; Analizar las

\footnotetext{
${ }^{1}$ carojedaleal@gmail.com

Copyright (C) 2014 (Ojeda, C.). Licensed under the Creative Commons Attribution Non-commercial No Derivatives. Available at http://cidades.dinamiacet.iscte-iul.pt/ 
potencialidades del paisaje como recurso de desarrollo económico sustentable; y Proponer una serie de estrategias de valoración del paisaje adaptado a un lenguaje sencillo y de fácil interpretación.

La Metodología que propone este estudio es la etnometodología (Firth, 2011:12) de corte cualitativo. Para el análisis de los datos espaciales y estadísticos se utilizaron los siguientes software: ArcGis 10@, QGis Lisboa 1.8, Atlas.Ti@, Evernote@, Apache Open Office, Google Earth®.

Para el análisis de la información obtenida se realiza un proceso de triangulación general (Firth, 2011: 12) entre las preferencias manifestadas por los entrevistados y entrevistadas (Santander, 2011: 209; Priego González, 2009: 2); los datos socioeconómicos-demográficos obtenidos a través de bibliografía que ofrece la base de datos de la Biblioteca del Congreso Nacional de Chile ${ }^{2}$; y un mapa temáticos realizados a partir de imágenes satelitales obtenidas desde Google Earth $\odot$ y Arcgis web service que muestra los puntos relevantes de valoración del paisaje que los y las entrevistadas manifestaron.

Los instrumentos (Vieytes, 2009) a utilizar para obtener los datos sociales son entrevistas estructuradas a informantes clave (Anexo 2). Los informantes clave se escogieron por su relación con el territorio, especialmente sus actividades económicas, vivienda u profesión/ocupación (Anexo 1). Finalmente, se realiza un análisis intermedio del proceso de codificación discursivo (Vieytes, 2009:377) con el software Atlas.Ti@.

\section{Revisión bibliográfica: Aproximación conceptual a la Valoración del Paisaje}

En el marco de la gestión sostenible de los paisajes, la participación social se concibe como el vehículo que permite recoger las expectativas previas (Boisier, 2004: 29), analizar los problemas, establecer soluciones, exigir compromisos y evaluar su desarrollo (Berroterán e González 2010: 64-65). Desde esta perspectiva lo que se persigue es la puesta en marcha de un proceso de transformación social en el que el paisaje y sus valores se conviertan en el eje de la dinámica social planteada (LPC, 2011: 8).

Lo primero sería aceptar radicalmente que el que algunas de estas sociedades no tengan palabra para nombrar el paisaje no quiere en absoluto decir que se trate de sociedades y de culturas "sin paisaje" (Gómez-Mendoza, 2013: 13), al contrario de cómo se manifiesta Augustin Berque en sus cuatro requerimientos para que exista paisaje incluía el de la existencia de las palabras para designarlo: "el paisaje no reside solamente en el objeto, ni solamente en el sujeto, sino, en la interacción compleja de estos dos términos” (Berque, 1995). La complejidad de esta relación está dada (Baudrillard, 1971), justamente, por la interacción dicotómica de estos dos agentes sujeto/objeto - que por un lado nos hablan del paisaje percibido y, por otro, del paisaje material (Luna e Valverde, 2010: 77).

Esta dicotomía - Paisaje Percibido vs. Paisaje Material - supone la constante interacción entre una dimensión de características simbólico-culturales (Schafer, 2010) y otra de carácter físico - tangible - ya sea en estados naturales o artificiosos. A partir de esta noción ${ }^{3}$, podríamos señalar que el paisaje no existe sin un sujeto que lo observe y signifique aisladamente, como lo afirma Ravi Prabhu, del Centro Mundial de Agroforestería: "porque esta es la forma en que las personas viven realmente. No viven debajo de un árbol, viven en un paisaje integrado",

Las formas en que es posible evaluar, medir, valorar, preservar y manejar el paisaje son infinitas (LPC, 2010). La plasticidad que posee esta área de estudio interdisciplinar hace que sea posible de abordar desde distintas posturas e incluso es posible aplicar técnicas y métodos de otras disciplinas científicas, sin modificar con ello su comprensión (Muñoz-Pedreros, 2004: 139).

\footnotetext{
${ }^{2}$ Biblioteca del Congreso Nacional de Chile, obtenido desde: http://siit2.bcn.cl/mapoteca/comuna view?dato=Comuna\%20de\%20Maull\%C3\%ADn

${ }^{3}$ Blog de Pedro Silva: Sobre el Paisaje y el Territorio. Consultado el 29 de julio de 2014. Obtenido desde: http://territorioypaisaje.tumblr.com/post/57005895946/enfoque-tpt-click-aqui

${ }^{4}$ Ramirez, G. Ciencia del Paisaje: Una manera de ayudar a los formuladores de políticas presentes en la COP18 a gestionar mejor los recursos del mundo. Blog CIFOR, disponible en: http://blog.cifor.org/12526/ciencia-del-paisaje-una-manera-de-ayudar-a-los-formuladoresde-politicas-presentes-en-la-cop18-a-gestionar-mejor-los-recursos-del-mundo/
} 
¿Cuánto vale una belleza natural como la de un paisaje escénico? Para responder a esta pregunta debemos entender qué es lo que valoramos de tal o cual paisaje y por qué lo hacemos (Arriaza, 2004: 116). Estas preguntas son las que se plantean en conjunto diversas disciplinas científicas como la Psicología Ambiental, la Ecología del Paisaje (Mateo Rodríguez et al., 2004: 77), la Arquitectura (Meissner, et al., 2000: 33-34), la Geografía (Mateo, 2005: 2-5) y las Ciencias del Paisaje (Lowenthal, 1979).

Los valores estéticos, culturales, espirituales y personales que asignamos a los paisajes son diversos, a veces poderosos y en ocasiones, trascienden los aspectos económicos (Herzog e Bosley, 1992: 117). Sin embargo, en el momento de tomar decisiones sobre proyectos que pueden dañar un paisaje o disminuir nuestra capacidad de disfrutarlo (Busquets e Cortina, 2009: 240-243), no resulta conveniente afirmar que "no tiene valor monetario". Esto equivaldría a caer en una trampa, ya que los procesos de toma de decisiones en el sistema capitalista actual se basan principalmente en factores económicos (Harvey, 2000: 77).

La valoración de raíz económica se basa, ya sea en el deseo — oculto o declarado— de pagar por los beneficios derivados del ambiente natural, o en la disposición a aceptar el pago a fin de evitar cambios en esos beneficios (Priego González, 2009). Los economistas emplean varias técnicas para revelar los valores sociales e individuales de los recursos naturales las que incluyen métodos directos e indirectos basados en el mercado así como métodos de valuación ajenos al mercado: Métodos basados en el mercado, Técnicas de valuación económica ajenas al mercado y Método de valuación contingente (Castelli, 2007: 177-181).

La valoración de raíz estética y visual del paisaje (Laurie, 1975: 104) se diferencia de la valoración económica, principalmente en lo que las personas o habitantes de un territorio manifiestan su interés o elección de ciertos paisajes por sobre otros fundamentando sus razones en aspectos emocionales, estéticos, sensoriales, políticos (Riveros, 2013), culturales, de memoria y recuerdo (Sztulwark, 2005: 1), pero para ellos y ellas, sus paisajes tienen valores mucho más importantes que el monetario por sí sólo. Como lo manifiesta Ryszard Kapuscinsky: "Cada individuo tiene su propio mapa del mundo. El del niño no se parece al del adulto... Al hablar del mundo, cada cual tiene su propio mapa, su propia visión, su propia imagen, su propio paisaje” 5 .

La técnica más utilizada es la valoración del paisaje es el análisis de preferencias -que es el que se utilizó en este estudio en particular- que parte aceptando que el valor del paisaje está en función del número de individuos que le prefieren por sobre otros paisajes (Muñoz-Pedreros, 2004: 141). También es comúnmente utilizado el método para valorar la fragilidad del paisaje de parte de sus habitantes o de paneles de expertos, que integrado a la valoración de la calidad visual permite aplicar criterios de preservación y conservación para sitios específicos creando mapas de Unidades de Paisaje (Ojeda Leal, 2011: 5).

\section{Indicadores de vida de la comunidad en las diferentes áreas de análisis del estudio de caso. Aspectos que influyen en la valoración del paisaje para un desarrollo sustentable.}

\subsection{Aspectos demográficos y socio-económicos}

Se aprecia una variación negativa preocupante en cuanto a las proyecciones demográficas que se manejan del decenio 2002-2012 (Figura 1), es decir, la población se mantiene en una baja sostenida y considerable de 14,69\% (Arteche e Infante, 2010: 56). Esto se hace patente al ver las cifras de dependencia de adultos mayores las cuales aumentaron al doble en el 2012 y superan las regionales e incluso las nacionales: manifiestan abiertamente que Maullín “es una comuna de viejos” (Entrevistada 18).

\footnotetext{
${ }^{5}$ LAPIDARIUM IV, 2003.
} 
Tabla 1. Población por grupos de edad 2002 (intervalos etarios) y proyectada 2012.

\begin{tabular}{crrrrr}
\hline \multirow{2}{*}{ Edad } & \multirow{2}{*}{2002} & \multirow{2}{*}{ Proyectada 2012 } & \multicolumn{3}{c}{$\mathbf{( \% )}$ Porcentaje sobre el territorio } \\
& & & \multicolumn{1}{c}{ Comuna } & \multicolumn{1}{c}{ Región } & \multicolumn{1}{c}{ País } \\
\hline $0-14$ & 4.259 & 2.563 & 19,28 & 22,74 & 21,77 \\
$15-29$ & 3.062 & 2.743 & 20,64 & 24,07 & 24,56 \\
$30-44$ & 3.925 & 2.523 & 18,98 & 21,93 & 21,08 \\
$45-64$ & 2.845 & 3.579 & 26,93 & 22,33 & 23,08 \\
65 y más & 1.469 & 1.883 & 14,17 & 8,93 & 9,52 \\
\hline Total & 15.580 & 13.291 & 100 & 100 & 100,01 \\
\hline
\end{tabular}

Fuente: Censo 2002 y Proyección de Población 2012 realizado por el Instituto Nacional de Estadísticas (INE).

Uno de los resultados que arrojan las entrevistas es que la categoría de Actividades Económicas que existen realmente en la localidad se perciben de muy distinta forma para los organismos de gobierno nacionales como el Servicio de Impuestos Internos (Figura 1) y los habitantes (Tabla 2) que manifiestan la preponderancia de las actividades extractivas primarias de temporada por sobre las industrias manufactureras o tecnológicas.

Esto se ve expresado en las cifras de trabajadores por tamaño de la empresa ${ }^{6}$ en donde la comuna sólo emplea un promedio de 729 personas en empresas micro-pequeñas-medianas y más de 283 en grandes empresas el año 2007, mientras que en 2011 esas cifras se redujeron a que sólo contaba con 853 en empresas micro-pequeñasmedianas y ningún trabajador/a en grandes empresas.

Figura 1. Número de trabajadores por rama de actividad 2006-2010 Comuna de Maullín.

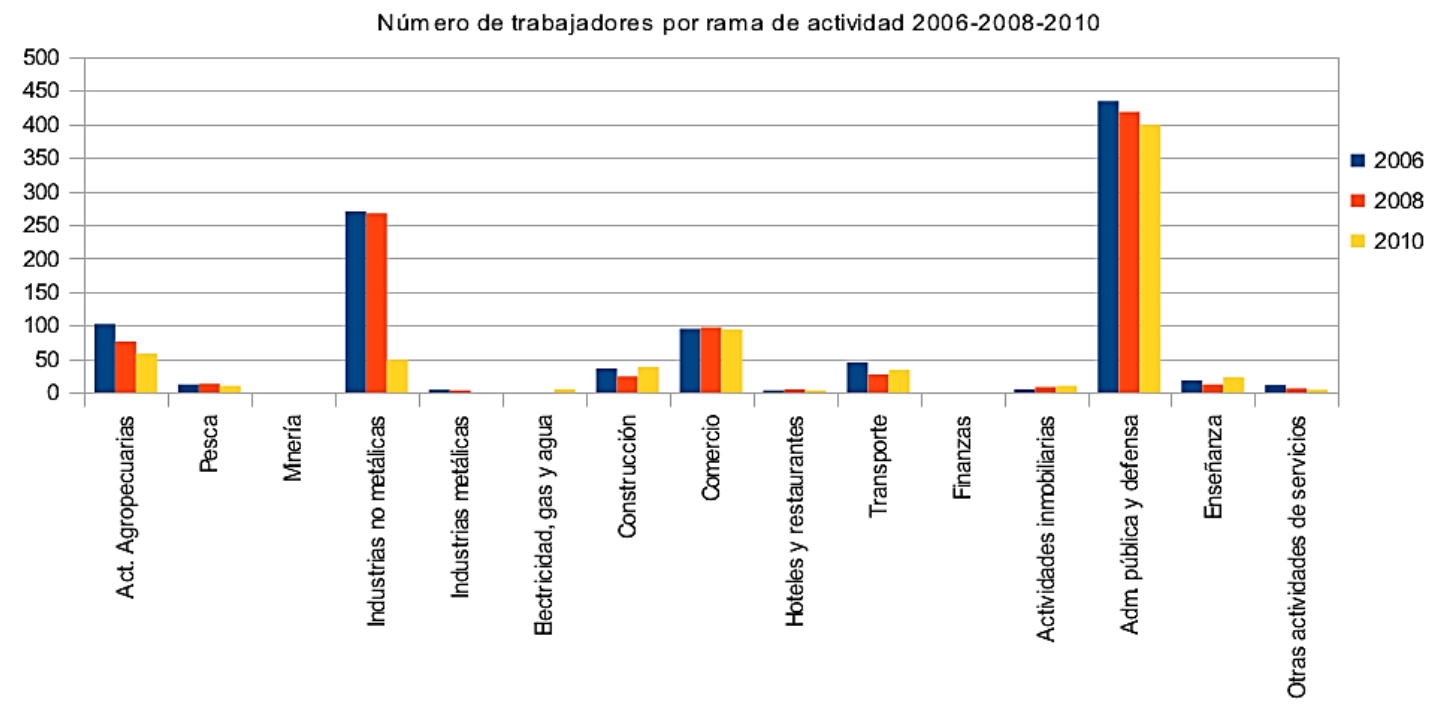

Fuente: Elaboración propia a partir de Servicio de Impuestos Internos (SII) y Biblioteca del Congreso Nacional 2012.

\footnotetext{
${ }^{6}$ Fuente: Servicio de Impuestos Internos (SII). (Consultado el 25 de julio de 2014). Disponible en: http://reportescomunales.bcn.cl/2013/index.php/Maull\%C3\%ADn\#Poblaci.C3.B3n_total_2002_y_proyecci.C3.B3n_2012_INE.
} 
Tabla 2. Rubros económicos descritos por los entrevistados/as.

\begin{tabular}{ll}
\hline pesca artesanal pesca (buceo) & pequeño comercio (importaciones) \\
pequeña agricultura & servicios públicos \\
silvicultura & Artesanías \\
pequeña ganadería y subproductos & turismo (rural / intereses especiales como avifauna-humedales)
\end{tabular}

Fuente: Entrevistas procesadas mediante ATLAS.TIC, 2013.

Quienes fueron entrevistados manifiestan que desean "más empresas que atraigan a los jóvenes, porque se están yendo de la comuna” (Entrevistada 12), pues sienten que las actuales ocupaciones no se traducen en un mayor desarrollo económico y social de la comuna, sino que por el contrario perciben que "los jóvenes no tienen en que trabajar... acá no hay mucho trabajo” (Entrevistado 2) (Tabla 3). Según cifras oficiales ${ }^{7}$ la tasa de ocupación comunal fue en 2011 de un 39,38\% siendo más baja que la del promedio regional 50,23\%, lo que es consecuente con la tasa de desocupación que correspondió en la comuna a un 10,90\% en 2011, superando a la media regional que fue de un $8,15 \%$.

Tabla 3. Población Ocupada, Desocupada e Inactiva.

\begin{tabular}{lrrrrrr}
\hline \multirow{2}{*}{ Territorio } & \multicolumn{3}{c}{ Categorías de empleo y población } \\
& \multicolumn{2}{c}{ Ocupados } & \multicolumn{2}{c}{ Desocupados } & \multicolumn{2}{c}{ Inactivos } \\
\cline { 2 - 8 } & $\mathbf{2 0 0 3}$ & $\mathbf{2 0 1 1}$ & $\mathbf{2 0 0 3}$ & $\mathbf{2 0 1 1}$ & $\mathbf{2 0 0 3}$ & $\mathbf{2 0 1 1}$ \\
\hline Comuna de Maullín & 5.362 & 4.220 & 144 & 516 & 5.715 & 5.980 \\
Región de los Lagos & 391.405 & 325.367 & 35.831 & 28.871 & 371.922 & 293.559 \\
\hline Total País & 5.994 .561 & 6.914 .037 & 643.977 & 579.050 & 4.995 .468 & 5.900 .029 \\
\hline
\end{tabular}

Fuente: Encuesta de Caracterización Socioeconómica Nacional (CASEN) 2003-2011, Ministerio de Desarrollo Social Chile.

Esto corresponde en muchas ocasiones a que el modelo o forma de desarrollo que existe en la comunidad se ha realizado de forma parcelada, desde arriba y con discrepancias entre el ordenamiento ecológico y social. Este modelo plantea una “urbanización estática y económicamente dependiente” (Malaspina, 2013) de los grandes polos de desarrollo económicos y culturales, creando una especie de Ciudades Dependientes de las capitales regionales y de los grandes centros productivos (Harvey, 2000).

\subsection{Medioambiente y Recursos Naturales}

El principal curso fluvial que recorre la comuna es el Río Maullín (412 28' S; $72^{\circ}$ 59' O) es preandino y se origina en el sector occidental del lago Llanquihue. Este río recorre una distancia de $85 \mathrm{~km}$, originando una cuenca que cubre $4298 \mathrm{~km}^{2}$ y con un caudal promedio de $72 \mathrm{~m}^{3} / \mathrm{s}$ (Niemeyer e Cereceda, 1984: 22). Desde su cabecera sigue en dirección al suroeste desembocando como un gran estuario en cuya costa sur se emplaza la ciudad de Maullín (MOP-DGA, 2004) (CONAMA, 2002).

\footnotetext{
${ }^{7}$ Fuente: Encuesta de Caracterización Socioeconómica Nacional (CASEN), Ministerio de Desarrollo Social. (Consultado el 25 de julio de 2014). Disponible en:

http://reportescomunales.bcn.cl/2013/index.php/Maull\%C3\%ADn\#Poblaci.C3.B3n_total_2002_y_proyecci.C3.B3n_2012_INE.
} 
Presenta en su curso vegetación ribereña de asociaciones endémicas de bosques pantanosos - conocidos como "hualves" - que albergan una amplia diversidad de flora y fauna, mucha de ella en peligro de conservación como el Huillín (Lontra provocax) y Chungungo (Lontra felina) (Sielfeld \& Castilla, 1990).

Allí se presentan grandes marismas estuarinas con poblaciones importantes de recursos marinos de interés comercial, poblaciones de algas, peces, moluscos y artrópodos, aves como los flamencos (Phoenicopterus chilensis), Cisne Coscoroba y Cisne de cuello negro que pasan el invierno en este sector (CONAMA, 2002). Muchos de sus habitantes sienten orgullo de esta característica de su comuna y la destacan por sobre otras:

“No en vano aquí está el desarrollo ornitológico principal del país...”

Entrevistada 17

El valor de estos ambientes, mayoritariamente humedales, son que cubren desde ambientes lóticos oligotróficos ritrales y potamales, incluyendo los Lagos Todos los Santos y Llanquihue - a gradientes de mesotrofía y eutrofía en la desembocadura (Fernández, et. Al., 2009:271). Desde el punto de vista geomorfológico, existe una serie de elementos fisiográficos que se pueden identificar claramente a simple vista, cuyos grupos principales son: Precordillera morrénica, Depresión Intermedia o Llano Central con Morrenas y Conos, Planicies Litorales (IGM, 1983).

Se aprecia como un elemento articulador al cuerpo fluvial - Río Maullín -, presentando un escenario que es reconocido por los habitantes, creando una suerte de paisajes de agua o Waterscapes (Herzog \& Bosley, 1992) que son vitales para la conformación de los imaginarios territoriales (Herzog, T., 1985):

“Somos privilegiados por tener río y mar, es un privilegio que no todos tienen. Me encanta el agua”

Entrevistado 4

"Las consecuencias del terremoto de 1960 en Maullín alteró significativamente el paisaje en cuanto a su morfología. Partiendo por el caudal del río Maullín y la inundación de distintas zonas que ha provocado la formación de diversos humedales siendo sitios de preservación y conservación de aves y fauna silvestre”

Entrevistada 14

Este tipo de ciudades que poseen elementos acuáticos relevantes y que reconocen su interacción con ellos, son posibles de planificar o manejar bajo el concepto de Water Sensitive Cities, un concepto australiano que está tomando cada vez más fuerza dentro del urbanismo contemporáneo que busca colocar en un sitial importante el agua y su manejo de forma sostenible y responsable, ya que como se sabe el agua puede ser un atributo o una amenaza para el ambiente (Villagra, 2013).

\subsection{Percepción del futuro de la comuna y Valoración del Paisaje}

A los y las entrevistadas se les consultó directamente sobre la percepción del futuro de su comuna que ellos/as poseían. La mayoría manifiesta que no existirá ningún cambio sustancial en Maullín:

"No me la imagino moderna, no creo que alguien haga un shopping mall..." 
Se manifiestan marcadas tendencias que divergen, a pesar de que la gente manifiesta que la comuna debe progresar y tener adelantos, lo que buscan es que se mantenga su identidad tradicional de comuna pequeña:

“Con más espacio para el trabajo y el comercio, pero sobretodo siendo la misma gente amable y cordial, que se vea el cariño entre vecinos".

Entrevistado 2

"Sin la intervención que le quite su identidad, sin un shopping mall ni cemento, respetando la identidad local (materiales nobles como la madera)".

Entrevistada 6

“Queremos que Maullín sea la capital nacional de los deportes acuáticos (yates, veleros, etc.)”

Entrevistado 7

“Además el tener contacto con la naturaleza hace valorar la importancia de esta y su preservación para las generaciones futuras. Algo totalmente opuesto a lo de grandes ciudades en donde las áreas verdes sólo se reducen a los parques... ¡Tener un árbol en casa es impagable!”.

Entrevistada 18

Sin embargo, existen personas que imaginan a su comunidad con una serie de adelantos en conectividad y servicios, más que en otras cosas que poseen las ciudades grandes:

“Con alta tecnología, agua potable en los campos, caminos asfaltados”.

Entrevistada 9

“Empleabilidad, salud (mejor acceso al hospital), mayor inversión privada, educación, emprendimiento”.

Entrevistado 6

"Me gustaría que haya un museo lindo"

Entrevistada 7

Estas tendencias tan contradictorias entre sí, son frecuentes de encontrar en comunidades que poseen un territorio vulnerable y un creciente fenómeno de desvinculación territorial entendida como un proceso de afiatamiento al territorio desvanecido debido a la enajenación del mismo. Además, se aprecia la vinculación que hacen algunos entrevistados entre el paisaje y el potencial económico: 
"Falta valorizar más el paisaje para fomentar el turismo como alternativa de trabajo (...) Más turismo basado en el río y sus paisajes”.

Entrevistada 16

“Acceso real a instancias de desarrollo sostenido y consolidado en el ámbito turístico” Entrevistado 14

“Si ponemos mucho empeño se ve un gran futuro con muchas personas visitando nuestra comuna”.

Dentro de lo que se expresa como valorado y apreciado son los paisajes naturales o que no poseen un alto grado de artificialización en sus geoformas (Laurie, 1975) (Priego González, 2009). Se observa que el Río Maullín y sus afluentes son los principales elementos estructuradores del paisaje terrestre; siendo las áreas costeras y el Oceáno Pacífico un segundo elemento estructurador; finalmente un tercer elemento es el bosque y el campo asociados a las riveras fluviales.

Los entrevistados/as valoran como un tipo de paisaje cultural - aunque no lo llamen así - la música como elemento articulador de su identidad territorial y comunitaria (Schafer, 2010; Luna \& Valverde, 2010). Valoran la existencia de suerte de Paisajes Sonoros (Soundscapes) en su comuna:

“Amplia vocación musical, patrimonio histórico, patrimonio editorial local”

Entrevistada 14

“A través de la música tratamos de mostrar el paisaje natural, mediante las canciones. Logramos una identidad musical patrimonial (...) Tenemos mucha juventud que hace cultura en música, bandas jóvenes”.

Entrevistado 4

Otros elementos importantes que modelan el paisaje en esta comuna son sus elementos bióticos. Se destacan principalmente la avifauna presente en los humedales y fauna marina. Los entrevistados/as reconocen la importancia de la presencia de estos habitantes que conforman su entorno, además de manifestar su preocupación por su conservación y manejo:

“Lo más hermoso que hay en el sur de nuestro país sobre todo en el tema de avistamiento de aves y el aire limpio”.

Entrevistado 2

“Falta de conocimiento normativa pesquera y ambiental”

Entrevistado 5

"El comportamiento de los habitantes en cuanto a su poco compromiso con el medioambiente” 


\subsection{Mapa de Puntos Especiales de Valoración de Paisaje relevantes}

Todos los elementos y tipos de paisajes nombrados anteriormente por los y las entrevistadas son claves para una posterior elaboración de mapas de Unidades de Paisaje (Ojeda Leal, 2011b) o mapas temáticos que presenten los puntos geográficos que poseen características especiales para ellos y ellas creando valoraciones emocionales y estéticas que van más allá del monetarismo (Ross, 2014: 12) (Figura 4), sin embargo, en ciertos tipos de paisaje como los sonoros (soundscapes), caminables (walkscapes), marinos (sailscapes) o culturales (cultscapes), nubosos (cloudscapes), terrestres (earthscapes), artísticos (artscapes); se hace más complicado su geoposicionamiento exacto debido a la falta de información que existe o la falta de redes que los agrupen.

Figura 4. Mapa de Puntos relevantes para la valoración del paisaje en búsqueda del desarrollo sustentable en la comuna de Maullín. Chile.

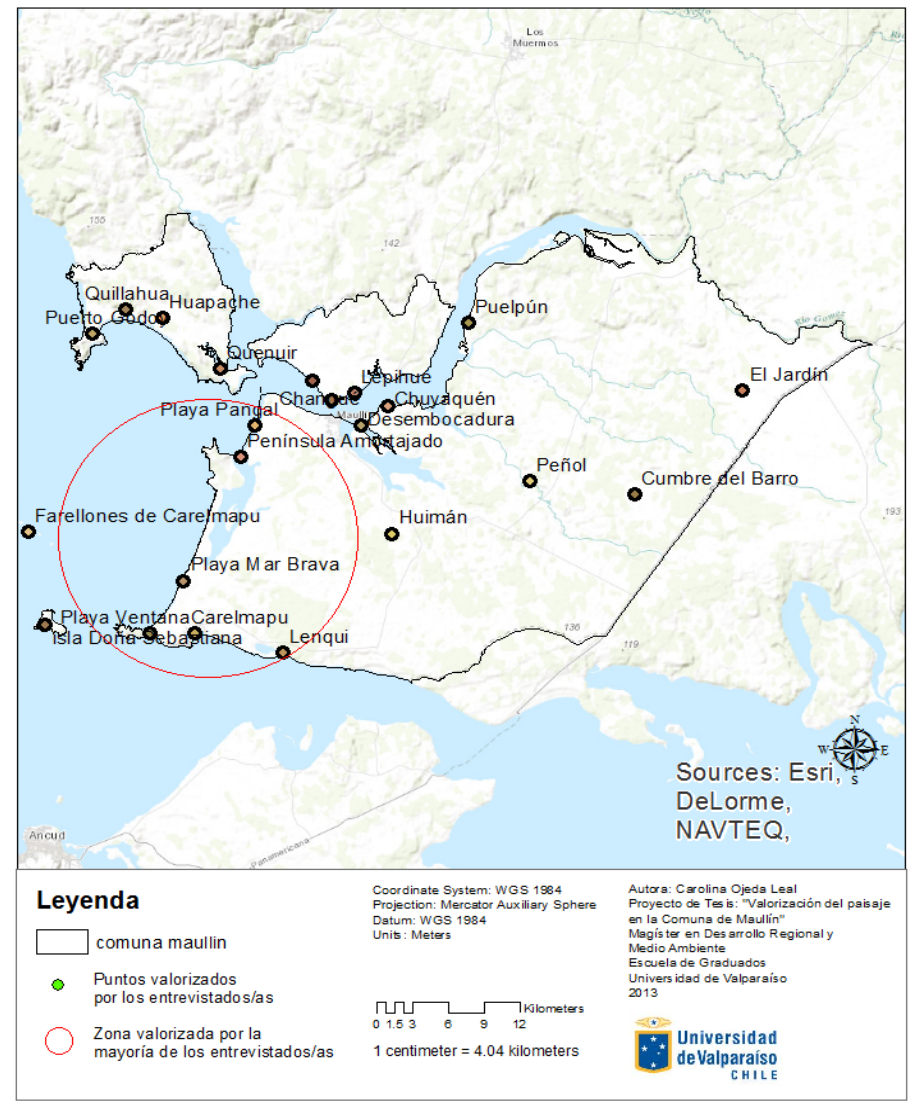

Fuente: Elaboración propia (2013) en base a entrevistas procesadas con software Atlas. Ti®.

Después de obtener las preferencias que mantienen los y las entrevistadas en materia de valoración del paisaje en su faceta estética y visual, es posible extraer ciertos puntos en el espacio que representan en su imaginario 
cotidiano lugares con una connotación especial, es decir, que ellos y ellas valoran por sobre otros paisajes de la misma comuna. Estos lugares coinciden con los que presentan mayor atractivo visual y estético natural por sus diversas geoformas constatado en varias visitas a terreno (Figura 5).

Estas preferencias apuntan a la manifestación que hacen sobre el paisaje que conocen y habitan, sin embargo los demás tipos de paisajes no son identificados como tales, remarcando la necesidad de crear una mayor conciencia sobre la valoración de todos los tipos de paisajes, pues todos ellos son en sí mismos generadores de potenciales recursos de desarrollo económico y sociocultural, además, de las consecuencias en su preservación y manejo como parte de su imaginario local.

Figura 5. Visita a terreno en la Desembocadura del Río Maullín, Chile.

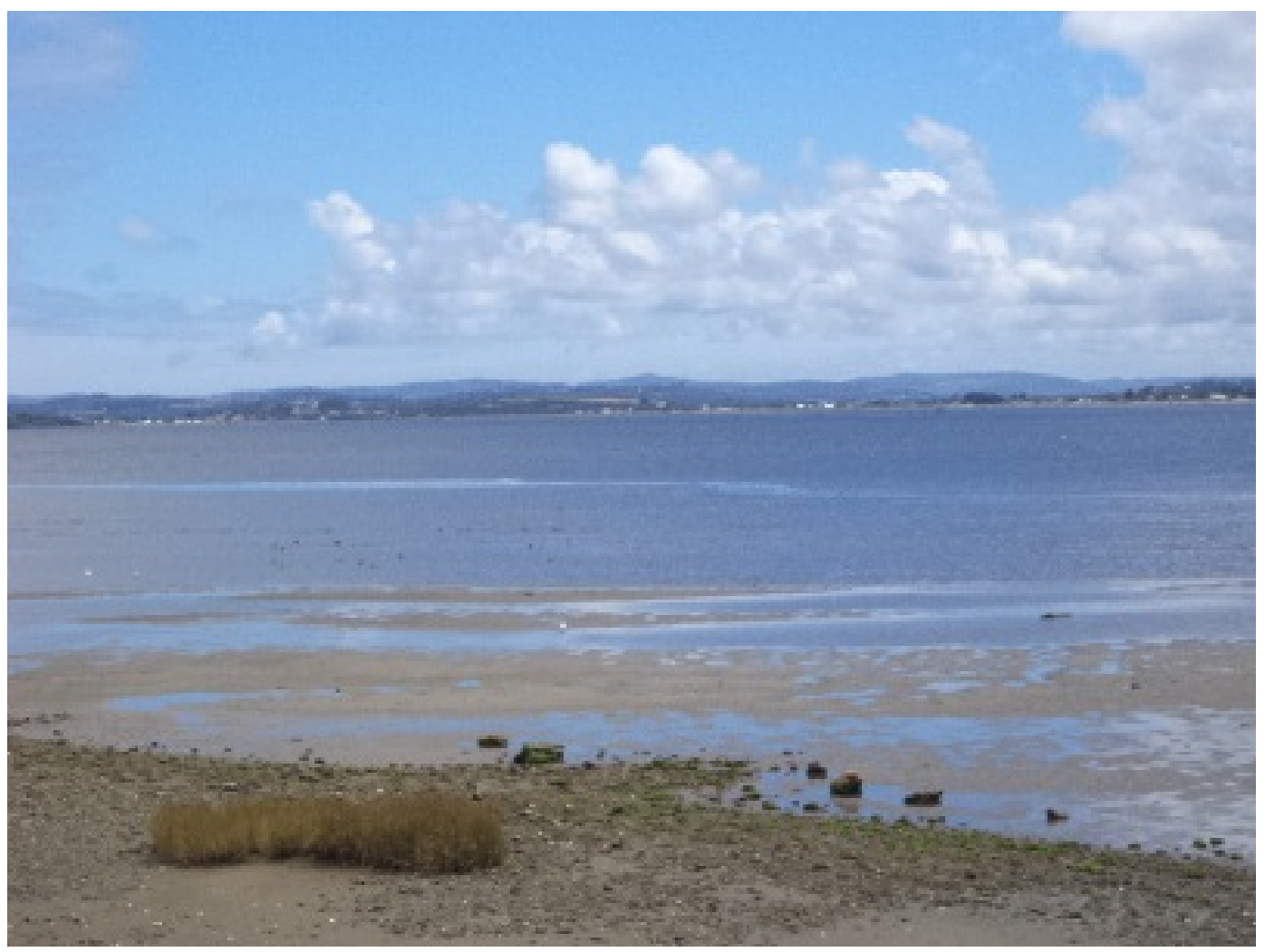

Fuente: Elaboración propia.

\section{Estrategias para la Valoración de Paisaje como un potencial recurso económico de desarrollo sustentable}

Los modelos de desarrollo actual plantean una seria disyuntiva par las comunidades pequeñas, las cuales muchas veces no poseen grandes centros fabriles o si los poseen no se sienten integrados - o beneficiados muchas veces de la presencia de estos centros en su territorio. Es por ello que una infinidad de economistas, sociólogos, politólogos, urbanistas, entre otros profesionales, han planteado formas de lograr este desarrollo de forma armoniosa con el medioambiente y las personas. Sin embargo, algo falta a la hora de implementar estos planes en la realidad: la inclusión activa de los agentes territoriales (stakeholders) en todo el proceso de planificación territorial y de estrategias de desarrollo. 
Las ideas que guían esta propuesta son básicamente la relación de simbiosis entre las comunidades y el ambiente que se da desde tiempos inmemoriales (Bocco, et. al., 2013), y que sin embargo, se ha perdido con el transcurso del tiempo y el avance de nuevas formas de vida más consumistas y centradas en ver al medioambiente como un objeto a ser dominado, más que un agente territorial como cualquier otro.

Esta propuesta no busca promover la 'moda' de la sustentabilidad y el capitalismo verde que hoy en día tiene tanto auge, sino que busca ayudar a las comunidades a reencontrarse a sí mismas con su medioambiente y sus habitantes de una forma respetuosa con sus propios valores, como reflexiona acertadamente el arquitecto Mario Pei: “Good architecture lets nature in”.

\subsection{Economía, Sociedad y Demografía}

Se propone como complemento en el sector económico la existencia de circuitos solidarios (Alister e Silva, 2013) como articuladores de la Economía Solidaria (Pastore, 2008) de carácter Sinérgica, la cual se basa principalmente en: Manejo de procesos económicos, consideración de base cultural patrimonial, acción estratégica con actores relevantes, y la consideración de prácticas económicas territoriales como las ferias libres, mercados locales, rutas turísticas, festivales costumbristas, economuseos, Rutas Ecoturísticas, Museos al Aire Libre y Bicipaseos (Dalla, 2013), entre otras ideas que surjan de las propias comunidades. Un ejemplo de buenas prácticas son las diferentes festividades locales que ya se realizan en la comuna, como por ejemplo la que presenta la comuna de Maullín, Chile. Esta economía se sustenta de las teorías de Desarrollo a Escala Humana que propone Max-Neef: "Desarrollo a Escala Humana (...) Tal desarrollo se concentra y sustenta en la satisfacción de las necesidades humanas fundamentales, en la generación de niveles crecientes de autodependencia y en la articulación orgánica de los seres humanos con la naturaleza y la tecnología, de los procesos globales con los comportamientos locales, de lo personal con lo social, de la planificación con la autonomía y de la sociedad civil con el Estado” (Max-Neef, Et Al., 2010)

Este tipo de economías se basan en un tipo de individuo o unidad productiva que no es única ni permanente en el tiempo, sino que reconoce la realidad que viven los pobladores-habitantes de los territorios rurales actuales, los cuales poseen estrategias productivas diversas que sostienen a la población y los flujos económicos: agropescador-temporero-asalariado-migrante (Alvarez, 2013). No existe un oficio primordial ni único, ajustándose a un calendario tradicional establecido consuetudinariamente.

Cada uno de estos proyectos - y hay una infinidad de ellos en todas las regiones del mundo - evidencia que la Economía Creativa está mejorando los medios de subsistencia en los países en desarrollo a nivel local. Los cauces que permitirán liberar aún más ese potencial constituyen el tema central de esta edición especial del Informe de las Naciones Unidas sobre la Economía Creativa 2013 (United Nations/UNDP/UNESCO, 2013).

Un hecho evidente que demuestran las estadísticas presentadas en los capítulos anteriores es la del envejecimiento de la población chilena y de la comuna de Maullín. Este proceso es inevitable y de muchas formas reversible, pues las estadísticas de crecimiento de población negativa se puede contrarrestar con un aumento de la población flotante y/o joven, es por ello que para hacer más favorable este proceso demográfico se podría implementar una serie de estrategias que apunten a dos grandes ejes: mejorar la calidad de vida de los adultos mayores destacando su rol dentro de la comunidad como portadores de la historia local (Soldavino, M. et. al, 2013) y su sabiduría en proyectos como el del Almanaque Agroecológico (Cortés, 2013), y atraer a los jóvenes y los migrantes con empleos o emprendimientos permanentes.

\subsection{Medio Ambiente, recursos naturales y ecopolítica}

Incorporar un marco ecológico en nuestra toma de decisiones económicas y políticas puede constituir de hecho más que una aspiración, una necesidad biológica (Guimaraes, 1991). Para que se puedan entender las implicaciones de la crisis ecoambiental, o sea ecológica (agotamiento de la base de recursos naturales) y 
ambiental (reducción de la capacidad de recuperación de los ecosistemas), pero a la vez ecopolítica, es decir, relacionada con los sistemas institucionales y de poder para la distribución de recursos (Montaña, 2012), se debe intentar comprender el proceso social que hay detrás de ella. Y las posible soluciones a la crisis deben encontrarse dentro del propio sistema social (Gallopin, 2003).

Por otro lado, el hecho de que tanto el Norte como el Sur sufran los impactos de la crisis, no implica que los países compartan los intereses respecto de las soluciones posibles (Ihl e Von Winterfeld, 2009). Aún en los casos en que puede emerger un interés compartido, ello ocurre cuando los intereses del Norte se ven afectados. Basta con recordar que la mayoría de los cambios globales que acaparan la atención internacional en la actualidad, llámese lluvia ácida, capa de ozono o efecto invernadero, son de responsabilidad casi exclusiva de los países del Norte (Franklin, 1996).

A esta crisis se llama ecosis, es decir, la "categoría para designar las consecuencias y cambios provocados por una sociedad sobre el medio natural, mediante acciones directas” (Portilla, 1965). En este sentido la ecología de saberes tiene un papel vital a través de la renovación constante de teorías críticas, rompiendo con las nociones coloniales del conocimiento, como la concepción que ve al otro como objeto no como sujeto (Solano, 2013: 2).

Como era de esperar, las autoridades de la mayoría de los países en desarrollo están dedicando una cantidad cada vez mayor de la atención a los consiguientes problemas en el uso de los residuos de la agricultura, forestales y la agroindustria - conocido como biomasa - (ONU World Hunger Programme, 2013), especialmente en zonas rurales o escasamente desarrolladas que poseen gran cantidad de estos residuos, los cuales son frecuentemente mal utilizados o destruidos.

Las necesidades más urgentes son la identificación y evaluación de los proyectos de bioconversión existentes y potenciales, pues estos residuos pueden ser transformados en combustibles - biocombustibles - o en productos reciclados manufacturados con valor agregado; la promoción de la investigación en el ámbito tecnológico en las comunidades rurales; la difusión de la información que ya existe en este campo y alianzas estratégicas promoviendo el emprendimiento local; y, la capacitación de los trabajadores seleccionados en estos países en desarrollo (ONU World Hunger Programme, 2013).

\subsection{Percepción de la comuna y valoración del paisaje}

El paisaje se considera aquí como un insumo de desarrollo para las comunidades, las cuales buscan desde sus orígenes el desarrollo sustentable y armónico con su entorno. Una de las condicionantes de este desarrollo basado en el paisaje es la de respetar las tres especificidades patrimoniales del paisaje: Visibilidad y legibilidad; Receptáculo integrador de elementos patrimoniales; adscrito al lugar, no transportable (Lowenthal, 1996: 77).

Estas especificidades apuntan a que se aprecie en su totalidad la "interpretación histórica y ecológica del paisaje en la base de la experiencia estética” (Venturi Ferriolo, 1999: 7). Así, el paisaje que se encuentra amenazado puede revertir estas condicionantes de vulnerabilidad y convertirse en un insumo para el desarrollo local efectivo.

Actualmente se aprecia la existencia de un enfoque lefebvriano de ciudad (Barahona, 2013), el cual se basa en la idea en que las ciudades se desarrollan como centros mercantiles, fuertemente influenciadas por la actividad agrícola desarrollada (Batten, 1964) en las zonas rurales, permaneciendo así hasta el día de hoy: "La revolución urbana se está desarrollando ante nuestros ojos y está borrando la relación entre la ciudad y el campo fundando a ambos en lo urbano... La naturaleza no es más que la materia prima sobre la que han operado las fuerzas productivas para producir SU espacio” (Lefebvre, 1972).

Es preciso re-ordenar el espacio de acuerdo a los principios del urbanismo sustentable con la idea fuerza de que los sistemas urbanos y rurales sean considerados como un solo gran sistema: el Continuum Urbano-Rural (Dewey, 1960) (Allen, 2011). Es por ello que los territorios que poseen características urbano-rurales marcadas necesitan de espacios para el diálogo ciudadano con distintas especificidades que los hacen diferentes a los 
espacios de diálogo que existen en las metrópolis: malls, plazas, cafés y redes de internet (Nevé, 2007; Ojeda Leal, 2011b: 22).

Se aprecia que existe una especie de zonas periurbanas, las cuales cambian continuamente sin ningún tipo de control o planificación estratégica. Estos cambios provienen de una expansión urbana que se caracteriza por estar presente en lugares donde las actividades económicas dominantes no son estables o transitan desde el declive de la agricultura a la falta de oportunidades de empleo rural (Allen, 2012: 135).

Específicamente, para la comuna de Maullín se propone que se maneje con criterios sustentables las tramas urbanas para evitar los fenómenos anteriormente descritos. Además, es necesario que la valoración del paisaje se fomente desde los planes comunales de ordenamiento territoriales, planes de turismo comunal, fomento económico, etc. Por otra parte la comunidad, se debe considerar como un actor principal dentro de este tipo de planificaciones e investigaciones.

Las entrevistas plantean un desafío metodológico, pues nos indican que la comunidad valora solamente un tipo de paisaje (paisaje natural) por sobre otros tipos de paisaje que existen en su comuna, lo cual presenta un llamado a que los profesionales del área y de disciplinas afines realicen capacitaciones para que se conozcan, valoren y preserven todos los paisajes de la comuna, especialmente aquellos que se encuentren amenazados como los sonoros y los culturales.

\subsection{Mapas de puntos relevantes en la valoración del paisaje}

Dentro de las estrategias mencionadas anteriormente se encuentra la de la utilización de elementos visualizadores gráficos que permitan observar e identificar de mejor forma las preferencias manifestadas por las personas que componen las comunidades locales que desean apostar por un proceso de planificación participativa en búsqueda de un desarrollo económico sustentable para su futuro inmediato (Solano, 2013: 77).

La imagen constituye una expresión sintética de la relación de las personas con su espacio y esto se cristaliza para las diferentes disciplinas de diferentes formas, para las ciencias geográficas en los mapas; para las arquitectónicas en las maquetas o presentaciones; para las ciencias sociales en las estadísticas y relatos. Este interés por la imagen en geografía humana se ha ido consolidando en torno a varios temas: “Algunos de los núcleos temáticos más reconocidos como parte de este rumbo son el paisaje, la percepción del espacio y la exteriorización de las imágenes mentales de los lugares, e incluso la cartografía, entre unos cuantos más. Al mismo tiempo, el interés por comprender estas cuestiones ha generado verdaderas perspectivas dentro de la teoría geográfica” (Lindón e Hiernaux, 2012: 9).

Este tipo de formas de hacer geografía, urbanismo, paisaje y arquitectura es particularmente reciente, por lo que aún se mantiene como una forma de validar datos o correlacionar objetivos, más que ser la forma en que los habitantes dialogan y comparten sus impresiones de forma horizontal con los investigadores/as desde el inicio de la misma, como lo relata Fiona Ross en su experiencia en Ciudad del Cabo, Sudáfrica: "llegar a conocer un espacio no es el mero producto de una relación visual con el paisaje, sino una relación corporeizada” (Ross, 2014: 5).

Estos mapas tienen las potencialidades de convertirse en herramientas de cartografía social, además, de poder utilizar de forma complementaria en ellos todos los instrumentos que ofrecen las ciencias sociales y del paisaje como: encuestas, entrevistas, mapeo colectivo o cartografía social, historias de vida, focos grupales, matrices FODA, árboles de problemas, entre otras (Álvarez, 2013).

En especial, para la comuna de Maullín es posible de utilizar desde diferentes perspectivas, tanto desde las autoridades locales como desde las empresas privadas u organizaciones sociales que quieran colaborar en este proceso. La colaboración de las universidades y centros de investigación es fundamental para este tipo de procesos, especialmente por el proceso de transferencia tecnológica. 


\subsection{Hacia un modelo de desarrollo económico social sustentable basado en el paisaje}

La propuesta considerada como resultado de este estudio consta de cinco etapas que son comunes a los proyectos de planificación para el desarrollo local-global: diagnóstico, planificación, aplicación de los instrumentos, ejecución y evaluación-seguimiento (Figura 6).

El esquema propone una síntesis de este tipo de planteamientos es una forma de contribuir al estudio del paisaje como elemento articulador del desarrollo regional y el medio ambiente. Posee cuatro grandes etapas y cuatro grandes agrupaciones de instrumentos para lograr su efectiva implementación:

\section{Diagnóstico:}

En esta etapa se propone un acercamiento a la realidad que sucede en la región o localidad a ser intervenida. Su principal cualidad es su carácter participativo, inclusivo y vinculante de todos los actores territoriales: empresas, pobladores, estado, centros investigativos (Universidades, colegios, etc.). Sus instrumentos propuestos son: diagnóstico participativo, propuestas desarrolladas por expertos, empresas y organizaciones sociales, expuestas en paneles informativos y talleres públicos.

\section{Planeamiento:}

En esta etapa se propone una planificación participativa e interdisciplinaria efectiva. Sus instrumentos propuestos son: presupuesto participativo, diferentes escenarios o planes propuestos por expertos/as, creación de Consejos Administrativos, y un buzón de sugerencias abierto para el público e instituciones.

3. Instrumentalización: En esta etapa se plantea la aplicación de instrumentos de valorización, evaluación y percepción tanto del paisaje como de las demás áreas que componen el desarrollo sustentable: económica, sociocultural y ambiental. También se busca realizar talleres y reuniones abiertas para evaluar el proceso que se lleva a cabo y definir cómo se ejecutarán los proyectos o instancias definidas por la comunidad. Se plantea además la existencia de alianzas estratégicas con los centros de investigación para la producción de artículos científicos y publicaciones para acrecentar - o crear - un acervo cultural local-global de las comunidades.

\section{Evaluación:}

La última gran etapa es la evaluación participativa del proceso vivido por la comunidad y sus actores territoriales. Esta evaluación se puede implementar mediante talleres y reuniones, paneles informativos públicos, programas de TV-Radio o en libros de divulgación científica. Se propone que a partir de esta etapa comience un proceso de seguimiento del proceso post-ejecución de a lo menos tres años, para tener una base sobre la cual obtener resultados y constatar las experiencias vividas por los habitantes del territorio. 
Figura 6. Esquema: Paisaje como potencial recurso de desarrollo económico sustentable.

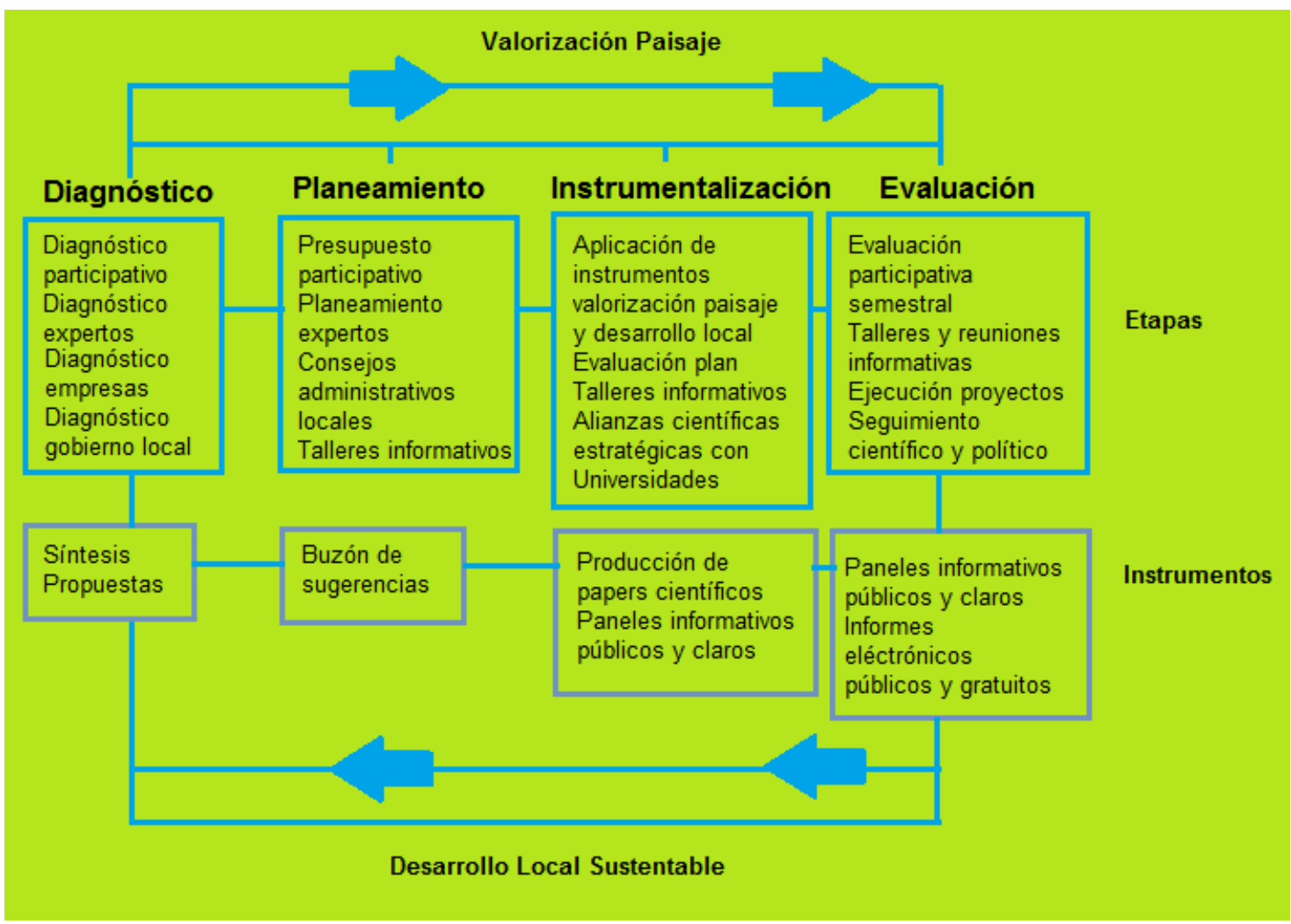

Fuente: Elaboración Propia, 2013.

\section{Conclusiones}

El paisaje es un constructo mental, una forma que permite comprender el territorio articulando elementos sociales, culturales, religiosos, geomorfológicos, de imaginarios, artísticos, etc. Como muchos/as autores/as han recalcado durante la breve existencia de la vida en la ciencia del paisaje, estos se puede categorizar de acuerdo a sus componentes y/o elementos estructurales. Se dividen principalmente en dos categorías: paisaje antrópico o cultural y paisaje protegido o natural.

A pesar de que todo/as los seres humanos/as somos capaces de apreciar, evaluar, valorar y calificar el paisaje; es sabido que sólo algunos/as experto/as se arrogan la facultad de realizar estudios e investigación sobre él. Más aún, en casos como el de Chile no existe legislación que proteja o estimule a la valoración del paisaje.

Mediante las respuestas que entregan los entrevistados/as se obtienen lugares o puntos que componen un mapa de puntos relevantes para la valoración del paisaje y, que si se potencian en su manejo, son capaces de convertirse en puntos importantes de desarrollo sustentable económica y socialmente. Además, fueron capaces de entregar valiosa información sobre la percepción que tienen sobre su medioambiente, paisaje, cultura, economía y sociedad.

El esquema que propone una síntesis de este tipo de planteamientos es una forma de contribuir al estudio del paisaje como elemento articulador del desarrollo regional y el medio ambiente. Posee cuatro grandes etapas y cuatro grandes agrupaciones de instrumentos para lograr su efectiva implementación.

El paisaje es posible de ser considerado un potencial recurso de desarrollo económicamente sustentable desde muchos puntos de vista y muchos autores/as proponen este tipo de desarrollo basado en el paisaje por ser un elemento aglutinador de las características ambientales y económicas, además de alcanzar un alto rango de reconocimiento social. 
Es interesante plantear que este tipo de estudios son fundamentales para los especialistas en desarrollo regional, territorial y medio ambiente, además, de urbanistas y autoridades de gobierno. Estos estudios entregan nuevas visiones sobre las posibilidades que tienen las comunidades y sus actores territoriales de generar nuevas formas de desarrollo económico y social con un componente sustentable en su fundamentación como lo es el paisaje. Es de esperar que estudios como este se sigan profundizando y desarrollando nuevos instrumentos, técnicas y herramientas para que las comunidades y los centros de estudio tengan una mejor interacción y esta sea recíproca en todos sus niveles.

\section{REFERENCIAS}

Alister, C., Silva, G. (2013), “Circuitos Económicos Locales. Una propuesta de desarrollo sustentable para las comunidades mapuche de la región de la Araucanía”, Conferencia presentada en el X Encuentro Nacional de Estudios Regionales, Sinergia Regional-Asociación Universidades Regionales-Universidad de Los Lagos, Noviembre 09-11, 2013, Puerto Montt.

Álvarez, R. (2013), “Cartografías participativas en isla Puluqui y proyecciones de desarrollo local”, Conferencia presentada en el X Encuentro Nacional de Estudios Regionales, Sinergia Regional-Asociación Universidades Regionales-Universidad de Los Lagos, Noviembre 09-11, 2013, Puerto Montt.

Angelsen, A., Vainio, M. (Eds.) (1998), Poverty and the environment, Bergen: CROP.

Arteche, V., Infante, D. (2010), “Potencial del Turismo Rural en la Comuna de Maullín”, Tesina presentada como requisito para optar al Grado de Licenciado en Administración, Puerto Montt, Universidad Austral de Chile.

Arriaza, M., Cañas-Ortega, J. F., Cañas-Madueño, J. A., Ruiz-Aviles, P. (2004), “Assessing the visual quality of rural landscapes”, Landscape and Urban Planning, 69, (1), DOI:10.1016/j.landurbplan.2003.10.029, pp. 115125.

Batten, T.R. (1964), Las comunidades y su desarrollo, México: F.C.E.

Baudrillard, J. (1971), La moral de los objetos. Función-signo y lógica de clase, London: Verso.

Benet, F. (1963), "Sociology uncertain: the ideology of the rural-urban continuum”, Comparative Studies in Society and History, 6, (1), pp. 1-23.

Berque, A. (1995), Les raisons du paysage, París: Hazan.

Berroterán, M.A., González M.Y. (2010), "Valoración Económica del Paisaje para la Gestión Sostenible del Área de Playa Puerto Viejo, Municipio Gómez, Estado Nueva Esparta, Venezuela”, Gestión Turística, (13), pp. 63-91. Obtenido desde: http://mingaonline.uach.cl_valoracion_economica_paisaje.pdf.

Bocco, G., Cinti, A., Urquijo, P. (2013), "La construcción social del paisaje en comunidades de pescadores artesanales”, Biblio 3W Revista Bibliográfica de Geografía y Ciencias Sociales, (Online), XVIII, 1012, pp. 1-24. Obtenido desde: http://www.ub.es/geocrit/b3w-1012.htm.

Boisier, S. (2004), "Desarrollo territorial y descentralización. El desarrollo en el lugar y en las manos de la gente”, Eure, XXX, (90), pp. 27-40.

Booth, K. (2010), “Cambiar las realidades globales: una teoría crítica para tiempos críticos”, Papeles de relaciones ecosociales y cambio global, (109), pp. 11-29. 
Busquets, J., Cortina, A. (2009), Gestión del paisaje: Manual de protección, gestión y ordenación del paisaje, Barcelona: Editorial Ariel.

Castelli, L., Sapallasso, V. (2007), Planificación y conservación del paisaje: herramientas para la protección del patrimonio natural y cultural, Buenos Aires: Fundación Naturaleza para el Futuro. Obtenido desde: http://www.naturalezaparaelfuturo.org.

CONAMA (2002), Estrategia Regional para la Conservación y Utilización Sostenible de la Biodiversidad; Décima Región de Los Lagos, Puerto Montt: Comisión Nacional de Medio Ambiente Décima Región de Los Lagos.

Cortés, L.M. (2013), “Almanaque Agroecológico, una guía cultural de Bogotá Rural”, Diario La Voz, Noviembre 29. Obtenido desde: http://www.semanariovoz.com/2013/10/09/almanaque-agroecologico-una-guiacultural-de-bogota-rural/\#more-9962.

Dalla, A.M. (2013), "La Musealización de la artesanía con escamas de pescado como medio de desarrollo sostenible y cambio social”, Conferencia presentada en el V Congreso de Educación, Museos y Patrimonio, DIBAM-ICOMOS-CECA Chile, Septiembre 30/octubre 01, 2014, Santiago de Chile. Obtenido desde: http://www.scielo.cl/scielo.php?script=sci_arttext\&pid=S0718$\underline{07052006000200008 \& \operatorname{lng}=\text { es\&tlng=es.10.4067/S0718-07052006000200008. }}$.

Dewey, R. (1960), “The rural-urban continuum: Real but relatively unimportant”, American Journal of Sociology, 1, pp. 60-66.

Fernández, L., Rau, J., Arriaga, A. (2009), “Calidad de la vegetación ribereña del Río Maullín (41o 28’ S; 72o 59’ W) utilizando el Índice QBR”, Gayana Botánica, 66, (2), pp. 269-278.

Firth, A. (2010), “Etnometodología”, Discurso y Sociedad, 4, (3), pp. 597-614.

Franklin, J. (1996), La Política de la Sociedad del Riesgo, Oxford: Polity Press.

Gajardo, R. (1994), Formaciones Vegetacionales de Chile, Santiago de Chile: Comisión Nacional de Medio Ambiente (CONAMA).

Gallopín, G. (2003), Sostenibilidad y Desarrollo Sostenible: un Enfoque Sistémico, Santiago de Chile: CEPALILPES.

García Redondo, J.M. (2012), "Sailscapes. La construcción del paisaje del Océano Pacífico en el Giro del Mondo de Gemelli Carreri”, Anuario de Estudios Americanos, (Online), 69, (1), pp. 253-275, DOI:10.3989/aeamer.2012.1.10, obtenido desde: http://estudiosamericanos.revistas.csic.es/index.php/estudiosamericanos/article/view/570/573.

Guimaraes, R. (1991), América Latina y los desafíos de la crisis ambiental, Lima: Centro Regional de las Naciones Unidas para la Paz, el Desarme y el Desarrollo en América Latina y el Caribe, Fundación Peruana para la Conservación de la Naturaleza, Fundación Friedrich Naumann.

Gómez-Mendoza, J. (2013), “Del patrimonio paisaje a los paisajes patrimonio”, Documents d'Anàlisi Geogràfica, 59, (1), pp. 5-20.

Harvey, D. (2000), Megacities. Lecture 4, Amersfoort, The Netherlands: Twynstra Gudde Management Consultants.

Herzog, T.R. (1985), “A Cognitive Analysis of Preference for Waterscapes”, Journal of Environmental Psychology, 5, pp. 225-241. 
Herzog, T.R., Bosley, P.J. (1992), “Tranquility and Preference as Effective Qualities of Natural Environments”, Journal of Environmental Psychology, 12, pp. 115-127.

Humboldt, A. (1874), Cosmos, New York: Penguin.

Ihl, M., Von Winterfeld, U. (2009), “Cambio climático, Sociedad y Sustentabilidad”, Revista Aspectos, Revista del Área Estado, Economía y Gestión, 7, pp. 47-64.

Instituto Geográfico Militar (IGM), Geografía de Chile, 9 vols. Santiago de Chile: IGM.

Laurie, I. (1975), “Aesthetic factors in visual evaluation”, in E. Zube, R. Brush, J. Fabos (Eds.), Landscape Assessment: Values, Perceptions and Resources, Stroudsburg: Dowden Hutchinnson and Ross, pp. 102-107.

Leff, E. (2005), "La geopolítica de la biodiversidad y el desarrollo sustentable: economización del mundo, racionalidad ambiental y reapropiación social de la naturaleza”, Conferencia presentada en el Seminario Internacional REGGEN: Alternativas a la Globalização, UNESCO, Octubre 8-13, 2005, Rio de Janeiro, Brasil. Obtenido desde: http://bibliotecavirtual.clacso.org.ar/ar/libros/reggen/pp12.pdf.

Lefebvre, H. (1970), La Révolution urbaine, Paris: Gallimard. Traducción al castellano (1972), La Revolución Urbana, Madrid: Alianza Editorial.

Lees, L., Slater, T., Wyly, E. K. (2008), Gentrification, London: Routledge.

Lindón, A., Hiernaux, D. (Eds.) (2012), Geografías de lo imaginario, México: Anthropos Editorial-Universidad Autónoma Metropolitana.

Lowenthal, D. (1979), Paysages et identités nationales, London: Verso.

LPC (LABORATORIO DEL PAISAJE CULTURAL) (2011), Recomendaciones técnicas para la participación social en la gestión de los paisajes culturales, Andalucía: Instituto Andaluz del Patrimonio Histórico. Obtenido desde: http://www.iaph.es/paisajecultural/documentos/recomendacion.pdf.

Luna, T., Valverde, I. (Eds.) (2010), Teoría y paisaje: reflexiones desde miradas interdisciplinarias = Theory and Landscape: Reflections from Interdisciplinary Perspectives = Théorie et paysage: réflexions provenant de regards interdisciplinaires, Barcelona: Observatorio del Paisaje de Cataluña - Universidad Pompeu Fabra. Obtenido desde: http://www.catpaisatge.net/fitxers/publicacions/teoria/paisaje/Teoria/y/paisaje.pdf.

Malaspina, O. (2013) “Paisajes Hidráulicos Complejos. Estudio de Caso: Olmos, Perú”, conferencia presentada en el Seminario Internacional Cultura del Agua: Paisajes, Territorios y Ciudadanía, Facultad de Arquitectura y Diseño - Universidad Diego Portales, Noviembre 12/13, 2013, Santiago de Chile.

Mata, R. (2013), "Paisajes para un desarrollo territorial sustentable y participativo”, Conferencia presentada en el I Simposio Paisaje y Territorio, Facultad de Arquitectura, Construcción y Diseño - Universidad del Biobío, Noviembre 6, 2014.

Mateo, J.M. (2005), “La concepción de los paisajes vistos desde la Geografía”, Documento de Trabajo Facultad de Geografía, Universidad de La Habana, La Habana.

Mateo Rodríguez, J.M., Da Silva, E.V., Cavalcanti, A.P.B. (2004), Geoecologia das Paisagens, Fortaleza, Brasil: Editora da UFC.

Max-Neef, M., Elizalde, A., Martin, H. (2010) [1986], Desarrollo a escala humana. Opciones para el futuro, Reprint, Madrid: Biblioteca CF+S.2010, Obtenido desde: http://habitat.aq.upm.es/deh/.

Meissner, E., Vilches, E., Lobos, V. (2000), Semiótica de la Arquitectura, Universidad del Biobío, Facultad de Arquitectura y Construcción. 
MOP/DGA (2004), Diagnóstico y clasificación de los cursos y cuerpos de aguas según objetivos de calidad. Cuenca del Río Maullín, Santiago de Chile: Ministerio de Obras Públicas (MOP)/Dirección General de Aguas (DGA).

Montaña, E. (2012), Escenarios de cambio ambiental global, escenarios de pobreza rural: una mirada desde el territorio, Buenos Aires: CLACSO. Obtenido desde: http://bibliotecavirtual.clacso.org.ar/clacso/clacsocrop/20121219121615/Escenariosd ecambioambientalglobal.pdf.

Muñoz-Pedreros, A. (2004), “La evaluación del paisaje: una herramienta de gestión ambiental”, Revista Chilena de Historia Natural, 77, pp. 139-156.

Niemeyer, H., Cereceda, P. (1984), Geografía de Chile, Santiago de Chile: Instituto Geográfico Militar (IGM).

Núñez, L. (2013), "Planificando territorios en países del Sur”, Conferencia presentada en el X Encuentro Nacional de Estudios Regionales, Sinergia Regional-Asociación Universidades Regionales-Universidad de Los Lagos, Noviembre 09-11, 2013, Puerto Montt.

Nurkse, R. (1955), Problemas de formación de capital en los países insuficientemente desarrollados, México: F.C.E.

Ojeda Leal, C. (2011a), “Análisis de fragilidad paisajística desde una perspectiva de género. Campus Concepción, Universidad de Concepción, Chile”, GeoGraphos: Revista Digital para Estudiantes de Geografía, (Online), $\quad 1, \quad$ (4), $\quad$ pp. $1-24 . \quad$ Obtenido desde: http://dialnet.unirioja.es/servlet/dcart?info=link\&codigo=3436073\&orden=286743.

Ojeda Leal, C. (2011b): "Estado del arte en las conceptualizaciones del paisaje y el paisaje urbano: una revisión bibliográfica”, GeoGraphos: Revista Digital para Estudiantes de Geografía, (Online), 4, (7), pp. 1-17. Obtenido desde: http://web.ua.es/revista-geographos-giecryal.

Pastore, R. (2008), "Diversidad de trayectorias, aproximación conceptual y pluralidad de proyectos de la Economía Social”, Documento del Centro de Estudios de Sociología del Trabajo, Facultad de Ciencias Económicas, Universidad de Buenos Aires.

Portilla, M.L. (1965), “Aculturación y Ecosis”, Anales de Antropología, II, pp. 131-136.

Prada, E., Maya, A. (2011), "Los paisajes rurales como factores de desarrollo territorial: la comarca zamorana de Sayago”, Conferencia presentada en el XI Coloquio Ibérico de Geografía en la Universidad de Alcalá de Henares, Alcalá de Henares, 2005. Obtenido desde: http://www.geogra.uah.es/web_11_cig/cdxicig/docs/01pdf_comunicaciones_coloquio/pdf-2/com-p2-11.pdf.

Priego González, C. (2010), "Espacios naturales en zonas urbanas. Análisis comparado entre las ciudades de Halle (Alemania) y las chilenas de San Pedro de la Paz y Talcahuano”, Revista Internacional de Sociología (Ris), 68, (1), pp. 199-224.

Riveros, R. (2013), "Paisaje y propuestas a las decisiones políticas para el desarrollo sostenible”, Conferencia presentada en el I Simposio Paisaje y Territorio, Facultad de Arquitectura, Construcción y Diseño - Universidad del Biobío, Noviembre 6.

Ross, F. (2014), “Paisajes sensoriales: sensación y emoción en el hacer del lugar”, Bifurcaciones, 16, pp. 1-20. Retrieved from: http://www.bifurcaciones.cl.

SAG (1976), Uso, Clasificación y Conservación de Suelos, Ministerio de Agricultura-Chile-Servicio Agrícola y Ganadero (SAG), Santiago de Chile: SAG.

Santander, P. (2011), "Por qué y cómo hacer Análisis de Discurso”, Cinta Moebio, (Online), 41, (1), pp. 207224. Obtenido desde: http://www.moebio.uchile.cl/41/santander.html. 
Schafer, R. (2010), Le paysage sonore, Paris: Wildproject.

Solano, M. (2013), “Imaginarios nacionales medioambientales en la espacialización comunitaria”, Serie Documentos de Trabajo Red de Posgrados, Santiago de Chile: CLACSO. Obtenido desde: http://bibliotecavirtual.clacso.org.ar/clacso/posgrados/20121227034502/OPMarianaSolanoUmanzor15.pdf.

Soldavino, M., Torres, M., Venegas, F. (2014), "Recordando el pasado porque yo estuve ahí. Y la maleta del recuerdo”, Conferencia presentada en el V Congreso de Educación, Museos y Patrimonio, DIBAM-ICOMOSCECA Chile, Septiembre 30/octubre 01, 2014, Santiago de Chile. Obtenido desde: http://www.scielo.cl/scielo.php?script=sci_arttext\&pid=S0718$\underline{07052006000200008 \& \operatorname{lng}=e s \& t \operatorname{lng}=e s .10 .4067 / \text { S0718-07052006000200008. }}$.

Staeheli, L., Mitchell, D. (2007), The people's property? Power, politics and the public, London: Routledge.

Sztulwark, P. (2005), “Ciudad Memoria, Monumento, lugar y situación urbana”, Revista Otra Mirada, (Online), 4, Obtenido desde: https://docs.google.com/document/d/1nQLzf_0kwY5NysShC5okfx5wFKwcvlNg_kMv1weNhPg/edit.

Ther, F. (2013), “Áreas Geoculturales Marítimas Costeras (AGMC) como posibilidad investigativa para visibilizar territorios-paisajes en el mar interior de Chiloé”, Conferencia presentada en el I Simposio Paisaje y Territorio, Facultad de Arquitectura, Construcción y Diseño - Universidad del Biobío, Noviembre 6, 2014.

Teixeira, S. (2006), “Educación Patrimonial: Alfabetización Cultural para la Ciudadanía”, Conferencia presentada en el V Congreso de Educación, Museos y Patrimonio, DIBAM-ICOMOS-CECA Chile, Santiago de Chile. Obtenido desde: http://www.scielo.cl/scielo.php?script=sci_arttext\&pid=S0718$\underline{07052006000200008 \& \operatorname{lng}=\mathrm{es} \& \mathrm{tlng}=\mathrm{es} .10 .4067 / \mathrm{S} 0718-07052006000200008}$.

UN/UNDP/UNESCO (2013), “Informe de las Naciones Unidas sobre la Economía Creativa 2013”, París: UN Press. Obtenido desde: http://www.unesco.org/culture/pdf/creative-economy-report-2013.pdf.

ONU World Hunger Programme (2013), “Utilization of biomass as a means for rural development”, Food and Nutrition Bulletin, 02, (1), pp. 1-70.

Vela-Ruiz, G., Del Mar, M. (2010), “Contribución del enfoque de desarrollo territorial rural a la comprensión de los procesos generados en torno a áreas protegidas en la Patagonia chilena”, Revista Chilena de Estudios Regionales, 2, (1), pp. 45-55.

Venturi Ferriolo, M. (2002), Estetica del paesaggio, Roma: Editori Riuniti.

Villagra, P. (2013), “Resiliencia y agua como indicadores de riesgos naturales”, conferencia presentada en el Seminario Internacional Cultura del Agua: Paisajes, Territorios y Ciudadanía, Facultad de Arquitectura y Diseño - Universidad Diego Portales, Noviembre 12/13, 2013, Santiago de Chile.

Vieytes, R. (2009), Metodología de la Investigación en organizaciones, mercado y sociedad. Buenos Aires: Editorial del Comercio. 
Anexo 1. Caracterización de la muestra de informantes clave

\begin{tabular}{|c|c|c|c|c|}
\hline Sexo & Edad & Oficio & Nivel Educacional & Tipo Organización \\
\hline$M$ & 25 & Geógrafo & Universitaria completa & ONG CECPAN \\
\hline$M$ & 23 & encargado centro juvenil & Universitaria incompleta & ENCARGADO OFICINA JUV \\
\hline $\mathrm{F}$ & 26 & secretaria del area social & media completa & Presidente Centro Padres E\$ \\
\hline $\mathrm{F}$ & 53 & artesana pescadora & media completa & Taller laboral Las Delicias de \\
\hline $\mathrm{F}$ & 35 & Independiente, agrícola, $\mathrm{p}$ & media completa & Taller laboral Zafiro \\
\hline$M$ & 40 & fotografo & Universitaria completa & fotografo \\
\hline $\mathrm{F}$ & 57 & artesana pescadora & media completa & artesana \\
\hline $\mathrm{F}$ & 56 & pescador artesanal, artesa & amedia completa & Unión Comunal Talleres Labd \\
\hline $\mathrm{F}$ & 54 & administrativo & media completa & Unión Comunal Talleres Labd \\
\hline $\mathrm{F}$ & 40 & instructor de tenis & media completa & Club de Tenis Angelo Parodi \\
\hline$M$ & 29 & sonidista y locutor radial & media completa & RADIO MAULLIN \\
\hline$M$ & 34 & Agente Zonal & Universitaria completa & BANCOESTADO \\
\hline$M$ & 56 & Director & Universitaria completa & COLEGIO JOSE ABELARDd \\
\hline$M$ & 33 & Agente Zonal & Universitaria completa & SERNAPESCA \\
\hline $\mathrm{F}$ & 56 & Gestión cultural Biblioteca & Universitaria completa & BIBLIOTECA MUNICIPAL \\
\hline$M$ & 27 & Director & Universitaria completa & DEPTO. TURISMO MUNICIP \\
\hline$M$ & 44 & Consejal y locutor radial & media completa & RADIO PANGAL FM \\
\hline $\mathrm{F}$ & 55 & dueña de casa y horticulto & OUniversitaria completa & TALLER LABORAL "LAS OR \\
\hline $\mathrm{F}$ & 37 & Auxiliar de farmacia & media completa & No Aplica \\
\hline$M$ & 30 & Auxiliar de farmacia & media completa & No Aplica \\
\hline $\mathrm{F}$ & 28 & Comerciante & media completa & No Aplica \\
\hline $\mathrm{F}$ & 49 & Profesora Básica & Universitaria completa & No Aplica \\
\hline$M$ & 37 & Comerciante & media completa & No Aplica \\
\hline$M$ & 41 & Agente Zonal CorreosChile & emedia completa & No Aplica \\
\hline$M$ & 40 & Patrón de nave menor, act & Básica completa & No Aplica \\
\hline $\mathrm{F}$ & 60 & Comerciante & Básica incompleta & No Aplica \\
\hline $\mathrm{F}$ & 61 & Dueña de casa & Básica incompleta & No Aplica \\
\hline $\mathrm{F}$ & 50 & Comerciante & Básica completa & No Aplica \\
\hline$M$ & 25 & Profesor Educación Media & auniversitaria completa & No Aplica \\
\hline $\mathrm{F}$ & 30 & Comerciante, dueña de hd & dUniversitaria incompleta & No Aplica \\
\hline$M$ & 28 & Agente Zonal CorreosChile & emedia completa & No Aplica \\
\hline
\end{tabular}




\section{Anexo 2. Pauta Entrevista Realizada}

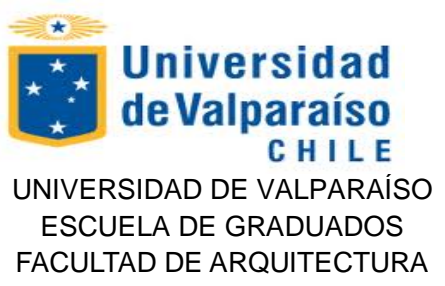

ENTREVISTA ESTRUCTURADA INFORMANTES CLAVE TESIS DE POSGRADO

"VALORACIÓN DEL PAISAJE DE LA COMUNA DE MAULLÍN COMO POTENCIAL RECURSO DE DESARROLLO ECONÓMICO SUSTENTABLE”

Estimado (a) entrevistado (a):

Junto con agradecer su participación en esta entrevista estructurada, nos es grato informarle sobre cómo se desarrollará la misma: este instrumento es anónimo, privado y será utilizado sólo con fines académicos. La institución que usted representa se considera como un informante clave, es decir, posee condiciones que lo hacen ser relevante en el quehacer económico, ambiental y social de la comuna.

\section{Sexo F M}

Edad

Institución a la que representa

1. ¿Desde hace cuánto vive en la localidad? (años)

2. ¿En qué trabaja? A qué se dedica? (Oficio o Profesión personal)

3. ¿Cuál es su nivel educacional formal? (básica, media, universitaria)

4. ¿Qué actividad(es) realiza con los vecinos/socios de su institución?

6. ¿Cuál(es) es(son) el(los) principal(es) problema(s) que su institución aprecia en la comunidad?

7. ¿Cuál(es) es (son) el(los) principal(es) potencialidad(es) que su institución aprecia en la comunidad?

8. Para su institución, ¿Cómo se definiría el paisaje?

9. Según la percepción que le da el trabajo en su institución: ¿Cómo se aprecia el paisaje en la comuna? ¿Se le da algún tipo de valoración al paisaje?

10. ¿Cómo se aborda el tema ambiental, el paisaje y el patrimonio en su institución?

11. ¿Cuáles son las actividades económicas que existen actualmente en su localidad?

12. ¿Cuáles son las actividades económicas que usted piensa serían posibles de realizar aquí?

13. ¿Cómo imagina su localidad en el futuro cercano? (20 años aprox.)

14. ¿Qué características culturales destaca o detesta de su comunidad? 
15. ¿Qué características del relieve (formas de la tierra) destaca o detesta de su comunidad?

16. ¿Cuáles son las mayores transformaciones que ha vivido la comuna? (Especifique los años o décadas aproximados que usted recuerde)

17. ¿Cómo percibe la relación de su institución con otros entes públicos y privados? (Ej: Municipalidad, GORE, salmoneras, organizaciones campesinas, etc.) 